\title{
A Constitucionalização da Função Social da Propriedade: Alteração na Dogmática do Direito Civil
}

\author{
Emanuel de Abreu Pessoa \\ Mestre em Direito pela UFC. Professor da UFC \\ e da FA7. \\ emanueldeabreu@hotmail.com
}

Sumário: Introdução. Desenvolvimento.

Conclusão. Referências.

Resumo: Historicamente, inclusive com o beneplácito das bulas papais, o direito de propriedade foi se absolutizando, tornando-se verdadeiro mantra dos civilistas da Idade Contemporânea em face da concepção liberal burguesa de propriedade consagrada pela revolução francesa, que manteve e aprofundou a visão romana do ius utendi (usar), fruendi (gozar) e abutendi (abusar/dispor). Esse viés absoluto foi consignado nas Constituições e nos Códigos que se seguiram. A Constituição mexicana de 1917 rompe com a sistemática liberal em prol do estabelecimento de direitos sociais nas Constituições, e a Carta de Weimar, em 1919, referendou, ainda que de forma tímida, a função social da propriedade, que serve como conformação ao direito de propriedade. A orientação do Direito Civil modificou-se, tornando-se mais atento ao princípio da socialização dos bens, sujeitando-se suas regras a inovadores princípios constitucionais de cunho social. A evolução das gerações de direitos fundamentais implica em evolução do conceito jurídico de propriedade. A rigor, é mais adequado se falar em dimensões e não em gerações de direitos fundamentais, porque a geração posterior não elimina as conquistas da anterior. Assim, com o avanço do Direito através da mudança de dimensões, o Direito Civil se torna menos absoluto, moldando-se pelas condições sociais e não apenas por uma ideologia liberal, sendo o grande exemplo dessa mudança em sua dogmática a evolução da propriedade, a qual é instituto civilista por excelência.

Palavras-chave: Propriedade. Função social. Constituição. 


\section{INTRODUÇÃO}

Para Rousseau, a propriedade seria o mais sagrado de todos os direitos dos cidadãos, sobressaindo-se inclusive em relação à liberdade, como chegou a se manifestar por ocasião de seus escritos na Encyclopédie (cf. COMPARATO, 1997), o que se revela coerente com sua tese sobre o surgimento da sociedade. Abolida a propriedade, estariam abolidos todos os direitos civis, pois eles se fundam sobre ela. A autoridade pública passaria a ser ilegítima, e seu reconhecimento se daria apenas pela força.

Consoante a teoria da natureza humana, a propriedade decorreria mesmo da natureza humana, constituindo, nos dizeres de Laurent, "expressão e garantia da individualidade humana, pressuposto e instrumento do nosso desenvolvimento intelectual e moral" (MONTEIRO, 1981, p. 82/83). Essa concepção foi defendida pelos partidários do direito natural, sendo válidas as observações dos que informam que a propriedade privada quase nunca deixou de existir (RODRIGUES, 1991, p. 81), e inclusive nas comunidades primitivas havia um certo senso nesse sentido, mas de propriedade coletiva, familiar ou tribal, e, com seu progresso, vai surgindo a propriedade privada, como que uma sua condição. Até mesmo nos países ditos comunistas não foi possível abolir por completo a propriedade privada.

Esta concepção, de um direito natural e inerente ao ser humano, o de propriedade, foi corroborada pela Igreja Católica. Com reiteradas encíclicas, ela contribuiu para a visão de um direito de propriedade que transcende razões legais, para ter uma fundamentação metafísica e divina. A propriedade privada foi defendida ostensivamente pela Santa Sé como forma de minar o avanço das teses socialistas e comunistas. Com o triunfo do Liberalismo, especialmente por conta das Revoluções Francesa e Americana, prevaleceu a teoria da natureza humana, de modo que a propriedade é encarada como algo inerente ao homem, servindo de oposição às concepções econômicas marxistas.

A propriedade, conforme as ideias burguesas, assumiu contornos de direito absoluto, garantindo assim o predomínio do poder econômico sobre a sociedade. Resgataram-se e se fortaleceram os seus atributos, já verificados na Roma antiga, a saber, o ius utendi, fruendi e abutendi, respectivamente a faculdade de usar, colher os frutos e dispor da propriedade, cujos contornos recebidos a absolutizaram.

Conforme a teoria constitucional então em voga, as Cartas Magnas cuidaram de positivar em seus textos o direito de propriedade, de forma que em um mundo repleto de desigualdades sociais e com forte concentração da riqueza em uma pequena camada da população, era verdadeiramente o Estado liberal instrumento de manutenção da dominação dos pobres pelos ricos.

Apenas com a erupção dos descontentamentos populares, quer através de protestos, greves, ou mesmo guerras e revoluções, foram sendo conquistados os direitos sociais, e entre eles uma releitura do direito de propriedade, reconhecendo-se sua função social. Diante de como o instituto se modificou ao longo do tempo, tem-se que admitir que, pelo menos parcialmente, a violência é mesmo a parteira da História. 
Como verdadeira conquista popular, a função social da propriedade também veio a ser positivada nos Códigos e nas Constituições, consoante a técnica legislativa adotada pelos países de civil law, alterando sobremaneira um dos dogmas liberais civilistas, a propriedade absoluta. Embora muito se fale sobre o que ela venha a ser, não são ainda numerosas as obras no meio científico brasileiro que discorrem sobre o surgimento e constitucionalização da função social da propriedade e sua importância como direito fundamental.

Assim é que nos propomos a proceder a tal análise, demonstrando como o direito de propriedade e sua função social são lados da mesma moeda, condições sine qua non entre si.

\section{DESENVOLVIMENTO}

Com a vitória da Revolução Francesa, consagrou-se o ideário liberal da burguesia, que, atinentemente à propriedade, pregava a liberdade de aquisição e fruição da mesma, sem a interferência do poder estatal ou a imposição de privilégios da nobreza, consubstanciando o adágio "laissez faire, laissez passer, le monde va de lui-même". À luz da primeira geração dos direitos fundamentais, consagradores do Liberalismo, era o direito de propriedade absoluto, o que se reprisou no art. 179, n. 22 da Constituição do Império do Brasil (1824).

Ainda seguindo a tradição liberal, a Constituição Republicana de 1891 traz em seu bojo similar disposição, especificamente no art. 72, § 17. O Código Civil de 1916 ainda sofreu tais influxos, perceptíveis no art. 524. Em 1917 irrompe a Revolução Mexicana, que quebra a sistemática liberal então dominante, em prol do estabelecimento de direitos sociais nas Constituições. Entretanto, foi a Constituição de Weimar que consagrou, ainda que de forma tímida, a função social da propriedade, em seus arts. 153 e 155.

Carl Schmitt teceu algumas considerações acerca do tratamento dado pela Carta de Weimar à propriedade privada, informando ser o texto contraditório e obscuro, apontando o desejo nela existente de relativizar a propriedade privada, que assim teria sua garantia com significado distinto daquele conferido à da liberdade pessoal (SCHMITT, 2003. p. 176-177). Mas aí há que se distinguir, pois a propriedade é tanto um direito natural que antecede o Estado quanto uma instituição legal. Todavia, a propriedade estaria garantida pelos dispositivos constitucionais dessa Carta, que se pretende a Lei Superior de um Estado burguês de Direito, que não existe sem a propriedade privada.

Estava-se, com a Constituição de Weimar, passando da primeira para a segunda geração de direitos fundamentais, isto é, dos direitos de liberdade (F reiheitsrechte) para os direitos sociais. Para Willis Santiago Guerra Filho, em vez de se falar em gerações de direitos, melhor se falar em dimensões, pois com o advento de uma nova 'geração', os direitos surgidos nas anteriores adquiririam nova conotação. Ele também afirma 
que "o direito individual de propriedade, num contexto em que se reconhece a segunda dimensão dos direitos fundamentais, só pode ser exercido observando-se sua função social, e com o aparecimento da terceira dimensão, observando-se igualmente sua função ambiental" (GUERRA FILHO, 2005. p. 47).

Sofrendo forte influência da Constituição de Weimar, a Carta brasileira de 1934 traz previsão indireta acerca da função social da propriedade em seu art 113, 17, ao discorrer sobre a vedação de sua utilização contra o interesse social ou coletivo, esboçando a migração de uma concepção meramente liberal acerca do direito de propriedade para uma concepção social. Na Carta de 1937, a previsão, ainda não explícita, tornou-se mais tímida, fazendo-se mera referência à lei para o estabelecimento do conteúdo e limites da propriedade, além de disposição referente à desapropriação por necessidade ou utilidade pública, no art. 122, 14.

Consoante a concepção fascista, que confunde o Estado e a Sociedade, a propriedade deveria então ser utilizada conforme o planejamento estatal, isto é, nos moldes previstos pela estrutura estatal, o que, em última análise, significaria que a propriedade estaria condicionada à visão corporativista do D ulce.

Claro está que até a Carta de 1937 (esta, inclusive) não se havia que falar em função social da propriedade nos termos atualmente conhecidos. O que havia, sendo a Constituição de 1934 a mais contundente a respeito, era a obrigatoriedade de a propriedade não ser posta contra o interesse social, e não sob este. Isto implica em omissão do proprietário diante do interesse social, e não em ação. Possível, pois, que se entenda não haver ainda sido introduzida no ordenamento jurídico brasileiro a função social da propriedade, e, sim, limites negativos à mesma, situação que se modificou com a Constituição de 1946, que em seu art. 147 condiciona a propriedade ao bem-estar social.

A expressão 'função social da propriedade', porém, foi utilizada pela primeira vez no Brasil pelo Estatuto da Terra (Lei n. $\left.{ }^{\circ} 4.504 / 64\right)$. O professor Raimundo Bezerra Falcão também faz referência, após citar o próprio Estatuto da Terra, a outros exemplos de positivação da função social da propriedade na legislação infraconstitucional, como no caso da Lei das Sociedades Anônimas (FALGÃO, 1981, p. 254).

Forçoso que concordemos com Darcy Bessone, segundo o qual "toda riqueza tem uma função social a desempenhar, e ao seu legítimo detentor corre o dever de conduzi-la conformemente à sua destinação - tal é o princípio da socialização dos bens" (1990, p. 18).

Finalmente, com a Constituição de 1967, positivou-se em âmbito constitucional a expressão 'função social da propriedade', em seu art. 157, III, a qual foi deslocada para o art. 160, por ocasião da Emenda Constitucional n. ${ }^{\circ}$ 1/69, a função social da propriedade deslocou-se para o art. 160, III.

É de se ver que o Brasil se encontrava, desde 1964, sob um regime ditatorial que primou por um regime econômico excludente. Tal estado de coisas, aliado ao forte êxodo rural do período, motivado pelas taxas vertiginosas de crescimento industrial, 
acentuaram as distorções quanto à propriedade rural, assim como quanto à propriedade urbana, eis que inegáveis os números assombrosos de sem-terra ${ }^{1}$ e sem-teto.

Com a redemocratização, veio a Constituição de 1988, cujo conteúdo decorre de uma reação da sociedade civil ao período de privação de direitos que se verificou na ditadura, repetindo situação similar à percebida na Inglaterra do pós-guerra $\left(2^{\mathrm{a}}\right.$ Guerra Mundial), quando, após longos sacrifícios, firmou-se uma concepção extremamente liberal de cidadania. Em seu bojo constam dispositivos acerca da função social da propriedade, a qual é consagrada no art. $5^{\circ}$, XXIII, que determina que a propriedade atenderá à sua função social, determinação erigida ao status de cláusula pétrea, não podendo ser suprimida por emenda constitucional $\left(\operatorname{art} .60, \S 4^{\circ}\right)$.

Não obstante, o inciso XXII traz disposição garantidora do direito à propriedade, revelando certa dicotomia do legislador constitucional originário. Partindo da lição de Luís Roberto Barroso, lembra Grace Tanajura que "o texto Constitucional foi redigido do particular para o geral e cada uma das comissões temáticas formadas por subcomissões em que se dividiu a Assembleia Constituinte elaborou um anteprojeto parcial, versando determinado tema" (2000. p. 27), de forma a que se desse a situação referida. A propósito, Magalhães Filho comenta que "é interessante observar que apesar da nossa Constituição mencionar a função social da propriedade, ela ainda continua a colocar a propriedade como objeto de direito individual". (2002. p. 220).

A função social da propriedade não é regra em sentido estrito, mas princípio, tendo duas funções, a saber, servir como instrumental e objetivo específico a ser alcançado, sendo princípio constitucional impositivo (GRAU, 2002. p. 269). Aliás, talvez a mais importante distinção ora existente em Direito seja a existente entre princípios e regras, ambas espécies do gênero norma, sendo esta uma expressão do tipo 'deve ser'.

De bom alvitre que a primeira das distinções a que façamos referência seja o elevado grau de abstração dos princípios, conquanto o mesmo se verifique de forma reduzida nas regras. A aplicação dos princípios requer aplicação de outros ou de regras, concretizando-os, por serem mandados de otimização, enquanto as regras, por prescreverem condutas, são de fácil aplicabilidade.

Os princípios possuem papel de destaque na hierarquia do ordenamento jurídico, situando-se acima mesmo das regras, fundamentando-as, ao que Canotilho alude ser sua função normogenética (1999, p. 1087). Aqueles se referem a uma ideia de justiça, podendo existir implicitamente no ordenamento jurídico, e estes se reportam a mandamentos de teor funcional.

\footnotetext{
3 Não obstante o termo, a referência se faz a todos aqueles que retiram sua subsistência do campo, sem, contudo, serem proprietários por razões alheias à sua vontade pura e simples, e não aos integrantes do MST ou seu congênere MLST.
} 
A moderna técnica constitucional prima pela positivação dos princípios, estando em voga o modelo misto do pós-positivismo, superando a mera codificação do Direito e reconhecendo a importância e normatividade dos princípios. O paradigma atual se inspira em teoria de Justiça, reabilitando-se a razão prática e a argumentação jurídica, desenvolvendo-se uma nova hermenêutica constitucional e uma teoria dos direitos fundamentais com base na dignidade humana. (cf. BARROSO, 2005, p. 4-5)

Ainda que não se cuidasse a propriedade de direito fundamental, essa é a posição à qual a mesma é alçada nos diversos textos constitucionais ao longo dos tempos, inclusive situada no Título II - Dos Direitos e Garantias Fundamentais da GF/88. Tal disposição é necessária em face da tendência de dominação e superioridade inerentes ao próprio Estado, consubstanciando, assim, garantia dos cidadãos em face do poder constituído.

Não obstante tivessem os antigos e os medievos noção do que fosse uma Constituição, pensavam os mesmos nas regras superiores como imanentes da ordem divina ou natural, o que se encontra substrato no paradigma filosófico se basear na ideia de essência, a qual existiria por si só.

Com a modernidade, o paradigma se desloca para o indivíduo, para a pessoa humana, verdadeira visão antropocentrista. As Constituições modernas (e contemporâneas) são documentos políticos que partem da limitação à atuação do poder estatal, no sentido de proteger as pessoas.

Esses limites consubstanciam os ditos direitos fundamentais. Paulo Ricardo Schier diz que "qualquer forma de regulação estatal não comprometida com a proteção de um núcleo de direitos fundamentais (e, logo, com o ser humano e o cidadão), não comprometida com a ética da modernidade e sua racionalidade, não é, propriamente, uma Constituição" (SCHIER, 2006. p. 24).

Não pode o legislador restringir os direitos e garantias fundamentais, salvo nos casos previstos pelo Constituinte originário, inexistindo cláusula geral de restrição dos direitos fundamentais, de maneira que estes não podem ser afastados, ainda que sob a alegação de 'supremacia do interesse público'. Nesse sentido, leciona Schier que “os direitos fundamentais "privados" deve integrar a própria noção do que seja o interesse público e este somente se legitima na medida em que nele estejam presentes aqueles. A regra, portanto, é de que não se excluem, pois compõem uma unidade normativa e axiológica" (SCHIER, 2006, p. 27-28).

Em se admitindo a propriedade como um direito fundamental, quer por o ser efetivamente, quer por o dizerem as Constituições, aplica-se a ela o brocardo latino ius et obligatio correlata sunt, sendo a obrigação correspondente o exercício da propriedade em conformidade com a sua função social.

É, portanto, a função social da propriedade cláusula constitucional de conformação do direito de propriedade. Válida a lição de Eros Grau (GRAU, 2002, p. 269), segundo 
o qual os princípios consubstanciam em seu bojo também diretrizes, no que adota a terminologia de Dworkin, ou normas-objetivo, que possuem caráter constitucional de conformador, justificando-se a reivindicação de se realizarem políticas públicas.

O caráter conformador da função social da propriedade não se confunde com uma restrição ao direito de propriedade. Cabível a lição de Canotilho sobre normas legais restritivas e normas legais conformadoras: aquelas restringem posições que, a princípio, seriam incluídas no campo de proteção dos direitos fundamentais, enquanto que estas se prestariam a complementar, precisar, concretizar ou definir conteúdo de um direito fundamental a ser protegido (CANOTILHO, 1999, p. 1185).

Francisco Fernandez Segado menciona que "a função social do direito não funciona como mero limite externo frente ao exercício do mesmo, senão como parte integrante do exercício do próprio direito, o que, por outro lado, não é senão a lógica resultante da consideração da função social da propriedade como elemento estrutural da definição da propriedade" (1992, p. 451). De fato, a função social da propriedade implica na incorporação do interesse geral junto ao individual do proprietário (1992, p. 450).

A propósito, a terminologia função social da propriedade foi inaugurada por Auguste Comte, no século XIX, sustentando que o positivismo vê uma função social da propriedade, que enobreceria a posse sem retirar a liberdade dela, tornando-a mais respeitada (cf. CHAVES, 2005. p. 32).

A Constituição de 1988 não faz menção à função social da propriedade unicamente em seu art. $5^{\circ}$, mas também o faz ao tratar da ordem econômica, no art. 170, III, sendo também consubstanciada no art. $5^{\circ}$., XXIV e XXV. Quanto ao que vem a ser a função social da propriedade, a Constituição Federal faz uma dicotomia entre a propriedade urbana e rural, sendo bastante explicativos os artigos correspondentes:

\footnotetext{
Art. 182. (omissis)

$\S 2^{\circ} \mathrm{A}$ propriedade urbana cumpre sua função social quanto atende às exigências fundamentais de ordenação da cidade expressas no plano diretor.

Art. 186. A função social é cumprida quando a propriedade rural atende, simultaneamente, segundo critérios e graus de exigência estabelecidos em lei, aos seguintes requisitos:

I - aproveitamento racional e adequado;

II - utilização adequada dos recursos naturais disponíveis e preservação do meio ambiente;

III - observância das disposições que regulam as relações de trabalho;

IV - exploração que favoreça o bem-estar dos proprietários e dos trabalhadores.
}

Não obstante a caracterização da função social da propriedade urbana esteja, por determinação constitucional, diretamente ligada ao Plano Diretor, parece-nos correto afirmar que ela se encontra precipuamente conectada às quatro funções básicas urbanísticas, a saber, a habitação, o trabalho, a recreação e a circulação. Desta forma, caso esteja a propriedade urbana sem se vincular a uma destas funções, não estaria ela a cumprir sua função social. 
Por conseguinte, assenta-se de grande importância os estudos de Direito Urbanístico, a permitirem uma exploração amiúde de tais funções urbanas e, assim, da própria função social da propriedade. Um dos grandes desafios da atualidade é a reforma urbana, de modo a assistir razão a Dimas Macedo, quando afirma que se quer que a política de uso do solo, em especial o urbano e o urbano criado, seja a que mais desperte atenção dos responsáveis pela atividade normativa e fiscalizatória do Estado, especialmente por ser a reforma urbana o maior dos desafios a serem enfrentados pelas aglomerações metropolitanas (2003. p. 34).

Sob o ponto de vista do princípio federal, interessante se perceber que o plano diretor é de elaboração dos Municípios, no que a função social da propriedade urbana estaria intimamente conectada a tal ente federado, corroborando o entendimento daqueles que afirmam que andou bem a Constituição em elevar as municipalidades a essa categoria. A respeito do tema, José Nilo de Castro pontua que cabe ao Município a competência constitucional para direcionar a função social específica da propriedade urbana (s.d., p. 234).

Quanto à propriedade rural, a Constituição Federal foi mais detalhista ao tratar de sua função social, redimensionando-a como direito de terceira geração, posto haver incluído entre seus requisitos preocupações de natureza ambiental.

Urge observar que a sociedade civil brasileira ainda não encampou completamente a ideia de função social da propriedade, como se percebe pelos terrenos não aproveitados em função da especulação imobiliária, da manutenção de latifúndios improdutivos e do contínuo desrespeito à legislação pertinente. Assim é que se faz necessário reconhecer que a constitucionalização da função social da propriedade, de per si, não tem o condão de realizá-la, faltando-lhe a aceitação de seus destinatários. Deve-se ter em mente que é o consentimento que permite à realidade normativa converter-se em realidade política, daí porque a função social da propriedade não deve ser vista como mera norma, mas posta em prática e aceita pela sociedade. A prudência constitucional, portanto, deve atentar para a efetividade que as normas constitucionais vão obter (VERDU, 2004, p. 6).

O princípio da força normativa da Constituição, que surge em contraponto à teoria de Lassale de que ela sucumbe aos fatores reais de poder, diz que se deve extrair dela a máxima eficácia possível em cada problema concreto, que se deve viver na Constituição, considerada vivida "em grande parte, porque é sentida pelo povo e aparece como símbolo político que tem razão de ser em virtude de sua função integradora" (VERDU, 2004, p. 7). Do mesmo modo, deve-se 'viver' a propriedade em sua função social, sob pena de a mesma ficar reduzida a mero enunciado legal, vazia de resultados práticos, perpetuando o status quo de exclusão social. 


\section{CONCLUSÃO}

A propriedade existe anteriormente ao Estado e ao Direito posto, tendo surgido pela simples apropriação individual das coisas existentes na natureza, condicionando toda a convivência humana a partir de então.

Ao longo dos séculos, a propriedade dos meios de produção, com destaque para a terra, foi causa dos principais conflitos e mesmo das revoluções que a humanidade conheceu, quer de forma direta, quer de forma indireta.

Com as revoluções liberais, a burguesia assumiu efetivamente o poder político, utilizando-o para consolidar seu poder econômico. Assim é que os contornos absolutos da propriedade se tornaram parte central do Direito Civil, sendo inclusive posta a propriedade como direto fundamental, titularizado pelos cidadãos em face do Estado, ficando este obrigado a respeitá-la da maneira mais ampla possível.

Os abusos do capitalismo liberal conduziram a diversas manifestações de revolta das camadas trabalhadoras e o surgimento de diversas ideias de cunho social, tais como o Marxismo, impondo modificações ao arcabouço fático-jurídico que se seguira à Revolução Francesa.

Desse modo, passou-se a cogitar de direitos sociais, também conhecidos como direitos de segunda geração, isto é, dimensão. Esses direitos são prestações do Estado em benefício dos cidadãos, e o surgimento dos mesmos levou a um redimensionamento dos direitos de primeira dimensão.

No caso da propriedade, a mesma passou a ser conformada pela sua função social, isto é, ela passou a integrar a essência da propriedade, transmutando-a. Dessa maneira, o direito fundamental à propriedade só é reconhecido como tal enquanto a propriedade atender à sua função social, sob pena de retrocesso a um sistema jurídico meramente liberal, individualista, contrariando a evolução do Direito.

\section{REFERÊNCIAS}

BARROSO, Luís Roberto. "Neoconstitucionalismo e constitucionalização do direito (O triunfo tardio do direito constitucional no Brasil)." Revista de Direito Administrativo N: 240. Rio de Janeiro: Renovar, 2005.

BESSONE, Darcy. Renovação de locação. 2 ed. São Paulo: Saraiva, 1990.

CANOTILHO, José Joaquim Gomes. Direito constitucional e teoria da Constituição. 3 ed. Coimbra: Almedina, 1999.

CASTRO, José Nilo de. Direito municipal positiva. 2 ed. Belo Horizonte: Del Rey, s.d. CHAVES, José Vander Tomaz. Da função social dos contratos no di reito brasileiro ante a disciplina jurídica da propriedade funcionalizada (Dissertação de Mestrado). Fortaleza: UFG, 2005. 
FALCÃO, Raimundo Bezerra. Tributação e Mudança Social. Rio de Janeiro: Forense. 1981.

GRAU, Eros Roberto. A Ordem Econômica na Constituição de 1988. 11 ed. São Paulo: Malheiros, 2006.

GUERRA FILHO, Willis Santiago. Processo constitucional e direitos fundamentais. 4 ed. São Paulo: RCS, 2005.

COMPARATO, Fábio Konder. "Direitos e Deveres Fundamentais em matéria de propriedade". Brasília: Revista CJF no 3, dezembro/1997.

MACEDO, Dimas. Política e constituição. Rio de Janeiro: Lumen Juris, 2003.

SCHIMITT, Carl. Teoría de la Constitución. Madrid: Alianza Universidad Textos, 2003.

MAGALHÃES FILHO, Glauco Barreira. Hermenêutica e unidade axiológica da Constituição. Belo Horizonte: Mandamentos, 2002. p. 220

MONTEIRO, Washington de Barros. Curso de direito civil: direito das coisas. 20 ed. São Paulo: Saraiva, 1981.

RODRIGUES, Sílvio. Direito civil: direito das coisas. 19 ed. São Paulo: Saraiva, 1991.

SCHIER, Paulo Ricardo. "Ensaio sobre a supremacia do interesse público sobre o privado e o regime jurídico dos direitos fundamentais”. RT 845. São Paulo: RT, 2006.

SEGADO, Francisco Fernandez. El sistema constitucional español. Madrid: Dykinson, 1992.

TANAJURA, Grace Virgínia Ribeiro de Magalhães. Função social da propriedade rural: com destaque para a terra, no Brasil contemporâneo. São Paulo: Ltr, 2000.

VERDU, Pablo Lucas. O sentimento constitucional: aproximação ao estudo do sentir constitucional como modo de integração política. Rio de Janeiro: Forense, 2004. 


\section{THE CONSTITUTION AND THE SOCIAL FUNCTION OF PROPERTY IN CIVIL LAW}

Abstract: Historically, the property right became absolute, a true mantra of the Contemporaneous Age's Civil Law scholars in face of the burgeois liberal conception of property sacred by the French Revolution, which kept and deepened the Roman view of ius utendi (to use), fruendi (to perceive fruits) and abutendi (to alienate). This absolute viewpoint was also consigned in the Constitutions and Codes that followed. The 1917 Mexican Constitution drifts away from the liberal systematic in benefit of establishing social rights in the Constitutions, and the 1919 Weimar Charter, asserted the social function of property, even in a discreet manner. The Civil Law orientation changed, becoming more attentive to the principle of socialization of goods, getting its rules under newfangled constitutional principles of social temper. The evolution of fundamental rights implies in changes of the juridical concept of property. Thus, with the advancement of Law through over the centuries, Civil Law becomes less absolute, molded by social conditions and not only by a liberal ideology.

Keywords: Property. Social function. Constitution. 